\title{
HUBUNGAN ANTARA SELF EFFICACY DENGAN HASIL BELAJAR KOGNITIF SISWA PADA MATERI FUNGI DI SMAN 1 CIHAURBEUTI
}

\author{
Yuyu Rahayu', Euis Erlin², Taupik Sopyan ${ }^{3}$ \\ 1,2,3 Program Studi Pendidikan Biologi Universitas Galuh, Jl. R. E. Martadinata No.150, Ciamis, Indonesia \\ e-mail: erlineuis@yahoo.com
}

\begin{abstract}
Self efficacy is a psychological factor in students that has a role to influence their cognitive learning outcomes. Students who have high self-efficacy will achieve high cognitive learning outcomes and vice versa. The purpose of this study was to determine the relationship between self-efficacy and students' cognitive learning outcomes on fungi. The time of the study was from February to July 2021. The population of this study were students of class X MIPA SMAN 1 Cihaurbeuti. The samples used were students of class X MIPA 1, amounting to 36 people. Sampling using cluster random sampling technique. This study uses a descriptive correlational method. The instrument used was a self-efficacy questionnaire and documentation of the results of the cognitive assessment of fungi. The results showed that there was a positive and significant relationship between self-efficacy and students' cognitive learning outcomes on fungi. This is indicated by a correlation value of 0.864 , which means that the correlation is very high and tcount ttable, which is 10.072 .04 at a significance level of $5 \%$, meaning that there is a positive and significant relationship.
\end{abstract}

Keywords: self efficacy, cognitive learning outcomes, fungi

\begin{abstract}
ABSTRAK
Self efficacy merupakan faktor psikologis dalam diri siswa yang memiliki peran untuk mempengaruhi hasil belajar kognitifnya. Siswa yang memiliki self efficacy tinggi akan mencapai hasil belajar kognitif yang tinggi pula begitupun sebaliknya. Tujuan penelitian ini adalah untuk mengetahui hubungan antara self efficacy dengan hasil belajar kognitif siswa pada materi fungi. Waktu penelitian dari bulan Februari sampai bulan Juli 2021. Populasi penelitian ini adalah siswa kelas X MIPA SMAN 1 Cihaurbeuti. Sampel yang digunakan siswa kelas X MIPA 1 yang berjumlah 36 orang. Pengambilan sampel menggunakan teknik Cluster random sampling. Penelitian ini menggunakan metode deskriptif korelasional. Instrumen yang digunakan angket self efficacy dan dokumentasi hasil penilaian kognitif materi fungi. Hasil penelitian menunjukan bahwa terdapat hubungan yang positif dan signifikan antara self efficacy dengan hasil belajar kognitif siswa pada materi fungi. Hal ini ditunjukan dengan nilai korelasi sebesar 0,864 yang artinya berkorelasi sangat

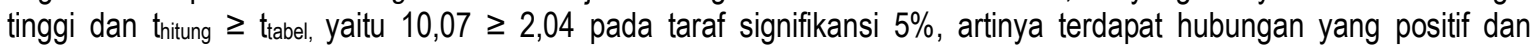
signifikan.
\end{abstract}

Kata kunci: self efficacy, hasil belajar kognitif, fungi

Cara sitasi: Rahayu, Y., Erlin, E., \& Sopyan, T. (2021). Hubungan Antara Self Efficacy Dengan Hasil Belajar Kognitif Siswa Pada Materi Fungi Di Sman 1 Cihaurbeuti. J-KIP (Jurnal Keguruan dan IImu Pendidikan), 2 (3), 259264. 


\section{PENDAHULUAN}

Pendidikan adalah usaha sadar yang dilakukan orang dewasa terhadap pihak lain yang belum dewasa agar mencapai kedewasaan dan untuk meningkatkan kualitas sumber daya manusia (Soelaiman dalam Rasyidin et al, 2017). Sehingga pendidikan merupakan hal penting yang harus dimiliki oleh setiap orang karena pendidikan mampu menentukan kualitas individu. Di Indonesia penyelenggaraan pendidikan merupakan suatu sistem pendidikan nasional yang diatur dalam Undang-Undang Negara Republik Indonesia Nomor 2 Tahun 1989. Dalam rangka meningkatkan kualitas pendidikan, salah satu usaha yang dapat dilakukan ialah dengan memahami siswa belajar.

Belajar dan mengajar pada dasarnya adalah interaksi atau komunikasi timbal balik antara guru dan siswa dalam pendidikan. Oleh karena itu guru dalam mengajar dituntut tegas, sabar dan bersikap terbuka supaya siswa lebih aktif dalam proses pembelajaran. Proses pembelajaran menekankan untuk pengembangan kompetensi agar mampu memahami suatu pembelajaran. Selain itu dalam proses belajar akan menghasilkan perubahan tingkah laku individu ke arah yang lebih baik dan peningkatan hasil belajar (Mulyono, 2015).

Purwanto (2011) menyebutkan hasil belajar merupakan perubahan perilaku setelah mengikuti pembelajaran yang sesuai dengan tujuan pendidikan dalam aspek kognitif, afektif, dan psikomotorik. Hasil belajar kognitif terdiri dari enam aspek, yakni pengetahuan atau ingatan, pemahaman, penerapan atau aplikasi, analisis, sintesis, dan evaluasi (Nurawaliah, 2021) Hasil belajar dapat dipengaruhi oleh dua faktor yaitu faktor internal dan faktor eksternal. Faktor internal yaitu dari dalam diri individu yang meliputi faktor fisiologis (fisik) dan faktor psikologis (jiwa). Sedangkan faktor eksternal yaitu dari luar diri individu yang meliputi faktor lingkungan sosial, faktor lingkungan nonsosial, dan faktor pendekatan belajar (Suryabrata dalam Dirma, 2019). Faktor psikologis yang mampu mempengaruhi hasil belajar salah satunya adalah self efficacy. Serupa dengan pendapat Schunk \& Meece (dalam Dirma, 2019) menyatakan bahwa self efficacy dapat memberikan pengaruh yang kuat terhadap hasil belajar siswa, karena self efficacy akan mempengaruhi kemampuan siswa dalam mengerjakan tugas, keseriusan atau ketekunan, dan prestasi siswa dalam pembelajaran. Oleh karena itu, seorang siswa harus mampu menghadapi pembelajaran sebagai tuntutan zaman yang semakin pesat. Self efficacy sangat diperlukan siswa agar mampu mencapai tujuan yang diinginkan.

Bandura (1997) mengatakan self efficacy adalah keyakian seseorang akan kemampuannya dalam mengatasi atau melaksanakan suatu tugas. Selain itu self efficacy merupakan keyakinan individu akan kemampuannya untuk mengendalikan diri dalam berbagai situasi dan kondisi yang terjadi. (Bandura, 2005). Alwisol (2007) juga berpendapat self efficacy adalah penilaian diri, yang dapat membedakan benar atau salah untuk mengerjakan sesuat sesuai dengan yang dipersyaratkan. Pada self efficacy terdapat tiga aspek sebagai indikator untuk mengetahui tingkatan yang menyebabkan keyakinan meningkat. Dimensi self efficacy menurut Bandura (1997), adalah level, strength, dan generality. Oleh karena itu, apabila siswa tidak memiliki keyakinan yang kuat untuk mengikuti pembelajaran dan mengerjakan tugas sekolah, maka siswa tersebut akan mengalami kegagalan dan kesulitan belajar.

Berdasarkan hasil wawancara yang dilakukan oleh peneliti dengan salah satu pendidik di SMAN 1 Cihaurbeuti yaitu guru mata pelajaran Biologi, beliau mengatakan bahwa hanya sebagian kecil siswa yang bersungguh-sungguh mengikuti pembelajaran. Apalagi dengan kondisi saat ini dimana pembelajaran dilaksanakan secara online sehingga banyak siswa yang tidak mengikuti pembelajaran dengan berbagai alasan salah satunya terkendala jaringan. Guru berusaha untuk mengoptimalkan pembelajaran. Usaha yang dilakukan guru diantaranya yaitu memberikan kesempatan kepada siswa untuk aktif bertanya, mengulangi materi yang belum dipahami siswa dan menciptakan kondisi belajar hangat dan penuh semangat. Peneliti tertarik ingin mengetahui hubungan antara self efficacy dengan hasil belajar kognitif siswa pada materi fungi, karena menurut guru yang bersangkutan, salah satu topik dari pembelajaran Biologi ini merupakan materi yang 
dianggap sulit dan banyak teori dan nama ilmiah sehingga tidak sedikit siswa yang bolos saat pembelajaran berlangsung.

Berdasarkan rumusan masalah diatas, maka tujuan dari penelitian ini adalah untuk mengetahui hubungan antara self efficacy dengan hasil belajar kognitif siswa pada materi fungi di SMAN 1 Cihaurbeuti.

\section{METODE PENELITIAN}

Penelitian ini menggunakan metode deskriptif korelasional dengan desain pola hubungan sebab akibat (kausal) (Sugiyono dalam Alminingtias, Soro \& Handayani, 2018), yang telah dilaksanakan pada bulan Februari sampai Juli 2021. Populasi pada penelitian ini adalah seluruh siswa kelas X MIPA yang terdiri dari tujuh kelas. Sampel yang digunakan kelas X MIPA 1 yang berjumlah 36 orang. Teknk pengambilan sampel menggunakan teknik cluster random sampling (Imam, 2020). Variabel dalam penelitian ini ada dua yaitu variabel dependen dan variabel independen. Variabel bebasnya adalah self efficacy, sedangkan variabel terikatnya adalah hasil belajar kognitif siswa. Instrumen yang digunakan dalam penelitian ini yaitu angket self efficacy dan dokumentasi hasil penilaian kognitif materi fungi.

Pengumpulan data dimulai tahap persiapan dengan merancang dan memvalidasi angket self efficacy serta melihat tujuan pembelajaran fungi dari silabus dan RPP yang dibuat oleh guru, tahap pelaksanaan penyebaran anget dan pengisian angket self efficacy oleh siswa serta melihat hasil kuis pembelajaran fungi, tahap analisis yaitu menganalisa hasil angket self efficacy siswa dan menganalisa hasil kuis pada materi fungi. Teknik analisis data pada penelitian ini menggunakan uji normalitas dan uji korelasional.

\section{HASIL DAN PEMBAHASAN}

Data yang dianalisis berupa hasil angket self efficacy dan hasil dokumentasi kuis materi fungi. Ringkasan hasil penelitian dari seluruh uji yang dilakukan sebagai berikut:

\section{Tabel 1. Ringkasan Uji Normalitas dan Uji Korelasi anatara Self Efficacy Dengan Hasil Belajar Kognitif Siswa Pada Materi Fungi di SMAN 1 Cihaurbeuti}

\begin{tabular}{|c|c|c|c|c|c|}
\hline Uji & Metode Statistik & Kriteria Uji & Nilai Uji & $\begin{array}{l}\text { Nilai } \\
\text { Daftar }\end{array}$ & Kesimpulan \\
\hline \multicolumn{6}{|l|}{ Uji Normalitas } \\
\hline Self Efficacy & \multirow[b]{2}{*}{ Chi Kuadrat $\left(X^{2}\right)$} & \multirow{2}{*}{$\begin{array}{c}\text { Normal jika } \\
X^{2}{ }_{\text {hitung }}<X^{2} \text { datar }\end{array}$} & 11,28 & \multirow[b]{2}{*}{11,3} & Berdistribusi Normal \\
\hline $\begin{array}{l}\text { Hasil Belajar } \\
\text { Kognitif Siswa }\end{array}$ & & & 3,03 & & Berdistribusi Normal \\
\hline Uji Korelasi & & & & & \\
\hline $\begin{array}{c}\text { Self Efficacy } \\
\text { dan Hasil } \\
\text { Belajar } \\
\text { Kognitif Siswa }\end{array}$ & $\begin{array}{l}\text { Pearson/ } \\
\text { Product } \\
\text { Moment }\end{array}$ & $\begin{array}{c}\text { Berkorelasi jika } \\
\text { thitung }>\text { tdaffar }^{\text {a }}\end{array}$ & 10,07 & 2,04 & $\begin{array}{c}\text { Berkorelasi Sangat } \\
\text { Tinggi }(r=0,864)\end{array}$ \\
\hline
\end{tabular}

Dari tabel diatas dapat diketahui bahwa berdasarkan hasil uji normalitas yang dilakukan pada taraf nyata $1 \%$ bahwa $X^{2}$ hitung $<X^{2}$ daftar yaitu $11,28<11,3$ pada self efficacy dan $3,03<11,3$ pada hasil belajar kognitif siswa. Dengan demikian menunjukan bahwa data yang diperoleh berdistribusi normal. Sedangkan untuk mengetahui hipotesis dari penelitian ini ada hubungan atau tidaknya menggunakan uji korelasi yang dilakukan pada taraf nyata $5 \%$ bahwa thitung $>t_{\text {daftar }}$ yaitu $10,07>2,04$. Dengan demikian hipotesis penelitian ini diterima. Berarti terdapat hubungan yang positif dan signifikan antara self efficacy dengan hasil belajar kognitif siswa pada materi fungi. Ha ini sejalan denga penelitian yang dilakukan oleh Safitri et al., (2019) menunjukan terdapat hubungan 
yang positif dan signifikan antara self efficacy dengan hasil belajar IPA siswa. Selanjutnya penelitian yang dilakukan oleh Sigiro et al., (2017) mengemukakan adanya hubungan antara efikasi diri dan hasil belajar biologi siswa kelas XI.

Berdasarkan hasil penelitian diatas diketahui bahwa self efficacy merupakan salah satu faktor yang mempengaruhi hasil belajar kognitif siswa. Hal ini terlihat pada hubungan self efficacy dengan hasil belajar kognitif siswa karena self efficacy yang muncul dari dalam diri siswa sangat tinggi, dengan demikian self efficacy yang bertujuan untuk mendorong siswa untuk berbuat, menentukan arah perbuatannya dan menyeleksi perbuatan tersebut untuk mendapatkan hasil belajar yang baik. Hal ini relevan dengan penelitian Seta (2014) bahwa hasil belajar merupakan suatu yang ingin dicapai siswa berkat adanya usaha dinyatakan dalam bentuk penguasaan sehingga nampak perubahan tingkah laku pada individu. Lebih lanjut, Sudjana (2005) menegaskan bahwa hasil belajar merupakan kemampuan yang dimiliki siswa setelah menerima serangkaian proses pembelajaran.

Self efficacy yang dimiliki oleh siswa kelas X MIPA 1 terbagi dalam tiga klasifikasi seperti yang tersaji pada tabel 2 .

Tabel 2. Klasifikasi Self Efficacy

\begin{tabular}{cccc}
\hline Klasifikasi & Skor & Interval & Presentase \\
\hline Sangat Tinggi & $X>102$ & 2 & $5,6 \%$ \\
Tinggi & $84<X \leq 102$ & 13 & $36,1 \%$ \\
Sedang & $66<X \leq 84$ & 21 & $58,3 \%$ \\
Rendah & $46<X \leq 66$ & 0 & 0 \\
Sangat Rendah & $X \leq 46$ & 0 & 0 \\
Jumlah & 36 & $100 \%$ & Jumlah \\
\hline
\end{tabular}

Dari tabel diatas dapat diketahui bahwa self efficacy yang dimiliki oleh siswa terbagi dalam tiga klasifikasi yaitu sangat tinggi memiliki skor yang lebih dari 102 berjumlah 2 orang dengan presentase $5,6 \%$, self efficacy tinggi memiliki skor antara 85 sampai 102 berjumlah 13 orang dengan presentase $36,1 \%$, self efficacy sedang memiliki skor antara 65 sampai 84 berjumlah 21 orang dengan presentase $58,3 \%$. Sebagain besar siswa memiliki self efficacy sedang sebanyak $58,3 \%$. Hal ini menunjukan bahwa sebagian besar siswa belum mempunyai keyakinan yang kuat akan kemampuan dirinya dalam melaksanakan pembelajaran untuk mencapai hasil yang diinginkan dalam belajar fungi, meskipun pada kenyataanya sudah ada beberapa siswa yang mempunyai self efficacy tinggi bahkan sangat tinggi dalam belajar fungi. Siswa yang memiliki self efficacy sedang disebabkan oleh beberapa hal yaitu kegagalan siswa dalam mata pelajaran Biologi sebelum materi fungi. Ketika siswa pernah gagal saat ulangan ataupun latihan pada materi sebelumnya, siswa yang memiliki self efficacy sedang akan merasa ragu bahwa mereka dapat menyelesaikan ulangan maupun tugas-tugas Biologi selanjutnya. Hal ini sejalan dengan pendapat Bandura (1997) menerangkan bahwa seseorang yang memiliki self efficacy tinggi akan menganggap kegagalan merupakan akibat dari keputusasaan dan kurangnya usaha dalam melaksanakan suatu kegiatan. Apalagi dengan kondisi saat ini dimana pembelajaran dilaksanakan secara daring (dalam jaringan) sehingga proses pembelajaran tidak berjalan dengan maksimal. Salah satunya terkendala jaringan sehingga siswa kurang bersemangat untuk mengikuti pembelajaran apalagi pada materi yang dianggap sulit dan kurang bersemangat untuk menyelesaikan tugas dengan lebih baik lagi kedepannya.

Untuk mengatur sebuah keyakinan, seseorang harus mengenali sikap dan kinerjanya terhadap suatu hal yang diinginkan. Hal ini relevan dengan pendapat Bockler (2017) menerangkan bahwa kondisi mental seperti pikiran dan keyakinan akan menjadi langkah awal untuk mencapai suatu tujuan. Oleh karena itu, seseorang individu harus mampu mengontrol dirinya sendiri untuk mencapai tujuan dalam hidupnya dan menjadi yakin juga tidak ragu-ragu dalam mencapai tujuan 
tersebut. Akan tetapi, jika kebutuhan fisiologis telah terpenuhi semua kebutuhan tersebut tidak mampu mendorong atau memotivasi. Bockler (2017) menambahkan bahwa keadan mental seseorang dapat meningkatan kemampuan nya dalam memahami dirinya sendiri. Sejalan dengan pendapat Bandura (1997) bahwa self efficacy adalah hasil dari proses berfikir seseorang berupa keyakinan dan harapan untuk mengukur kemampuannya dalam melaksanakan suatu tugas sesuai tujuan yang ingin dicapai. Oleh karena itu, guru dan orang tua harus memberikan bimbingan dan pujian terhadap hasil pembelajarannya di sekolah, agar siswa mampu lebih meningkatkan lagi self efficacy pada dirinya sendiri sehingga akan memberikan usaha yang tinggi pula untuk meraih prestasi dalam pembelajaran, khususnya pada materi fungi.

\section{KESIMPULAN}

Setelah dilakukan penelitian dan menganalisis data yang diperoleh dalam pembahasan dapat disimpulkan bahwa terdapat hubungan yang positif dan signifikan antara self efficacy dengan hasil belajar kognitif siswa pada materi fungi. Self efficacy yang diperoleh terbagi dalam tiga klasifikasi yaitu sangat tinggi dengan presentase 5,6\%, tinggi dengan presentase $36,1 \%$, dan sedang dengan presentase $58,3 \%$.

\section{REKOMENDASI}

Rekomendasi dari penelitian ini adalah sebaiknya dikaji mengenai self efficacy dengan kemampuan berpikir yang lebih mengerucut pada materi yang lainnya.

\section{UCAPAN TERIMAKASIH}

Penulis mengucapkan terima kasih kepada kelas X MIPA 1 SMAN 1 Cihaurbeuti yang berjumlah 36 orang yang telah mendukung terhadap pelaksanaan penelitian ini.

\section{DAFTAR PUSTAKA}

Alminingtias, F. M., Soro, S., \& Handayani, I. (2018). Hubungan Self Efficacy dengan Hasil Belajar Matematika Siswa di MAN 7 Jakarta. Seminar Nasional Pendidikan Matematika. 1:365-371.

Alwisol. (2007). Psikologi Kepribadian. Malang. UMM Press.

Bandura, A. (1997). Self Efficacy: The Exercise of Control. New York: W. H. Freeman and Compani.

Bandura, A. (2005). Theories of Personality: Social Kognitive Theory. The Mc Graw-Hill Companies.

Bockler, A. et al. (2017). "Know Thy Selves: Learning to Understand Oneself Increases the Ability Understand Other". Journal of Cognitive Enhancement. 1(2): 197-209.

Dirma, H. (2019). Korelasi Self Efficacy dengan Hasil Pembelajaran Biologi pada Kelas XI SMA Negeri 1 Rambatan. Skripsi IAIN Batusangkar.

Imam. (2020). Cluster Random Sampling dan Teknik Sampling Lainnya, Lengkap dengan Contoh. [Online]. Tersedia: http://www.99.co/id/panduan/cluster-random-sampling-adalah. [16 Februari 2020].

Mulyono, N. (2015). Kurikulum dan Pembelajaran. Bandung. Rizqi Press. 
Nurawaliah, N., Rusyana, A., \& Sopyan, T. 2021. Pengaruh model discovery learning berbasis concept mapping terhadap hasil belajar kognitif. J-KIP (Jurnal Keguruan dan IImu Pendidikan), 2 (2), 33-38.

Purwanto. (2011). Evaluasi Hasil Belajar. Jakarta. Pustaka Belajar.

Rasyidin, W, et al. (2017). Landasan Pendidikan. Bandung. UPI Press.

Safitri, I., Yolida, B., \& Surbakti, A. (2019). "Hubungan Self Efficacy berdasarkan Gender dengan Hasil Belajar Siswa Mata Pelajaran IPA". Jurnal Bioterdidik. 7(3):32-40.

Seta, I. F. (2014). Korelasi antara Hubungan Sosial dan Self Efficacy dengan Hasil Belajar Siswa Kelas VIII SMP Negeri 6 Kota Bengkulu. Skripsi Universitas Bengkulu.

Sigiro, et al. (2017). "Hubungan Efikasi Diri dan Penalaran Ilmiah dengan Hasil Belajar Biologi Siswa SMA". BIOSFER: Jurnal Pendidikan Biologi. 10(2):30-34.

Sudjana, N. (2005). Penilaian Hasil Proses Belajar Mengajar. Bandung. Remaja Rosdakarya. 